\title{
Investigating the effect of educational intervention based on Theory of Planned Behavior on the preventive behaviors regarding microbial and radiation complications of mobile phone in female students of secondary school
}

Fatemeh Savari Mombeni

MSc, Department of Health Education and Health Promotion, Social Determinants of Health Research Center School of Public Health, Ahvaz Jundishapur University of Medical Sciences, Ahvaz, Iran.

Akbar Babaei Heydarabadi

* Assistant Professor Assistant Professor, Department of Health Education and Health Promotion, Social Determinants of Health Research Center, School of Public Health, Ahvaz Jundishapur University of Medical Sciences, Ahvaz, Iran. (Corresponding Author) babaeinmz2056@gmail.com

Naser Hatamzadeh

Assistant Professor Assistant Professor, Department of Health Education and Health Promotion, Social Determinants of Health Research Center, School of Public Health, Ahvaz Jundishapur University of Medical Sciences, Ahvaz, Iran.

Asad sharhani

Assistant Professor, Department of Biostatistics and Epidemiology, School of Public Health, Ahvaz Jundishapur University of Medical Sciences, Ahvaz, Iran.

Received: 2021/01/27

Accepted: 2021/03/18

Doi: 10.52547/ijhehp.9.2.159

\section{ABSTRACT}

Background and Objective: Mobile phone is one of the most important means of communication and social in the present age, and there are concerns about its harmful effects due to the growing use of it among adolescents. In this regard, the present study was conducted to determine the effect of educational intervention based on the Theory of Planned Behavior regarding microbial and radiation complications of mobile phone in female students of secondary school in Baghmalek city. Materials and Methods: The present study was a quasi-experimental two-group study (test and control) that was conducted on 100 students in 2019. The target population consisted of female high school students who entered the study using stratified sampling method. The educational intervention was conducted using the method of short lecture, group discussion, question and answer based on the constructs of the theory of planned behavior. The training sessions were conducted in the form of group training in the form of 3 sessions for 90 minutes during a month. Data analysis was performed using SPSS 24 software and independent t-test and paired t-test.

Results: The results showed that before the intervention, the mean and standard deviation scores of attitudes $(24.08 \pm 4.78)$, Subjective norm $(32.52 \pm 7.67)$, perceived behavioral control (32.28 \pm 5.05$)$, behavioral intention (13.14 \pm 4.44$)$ and behavior $(24.30 \pm 4.40)$ between the two groups of control and test were not significantly different $(P<0.05)$. However, one month after the educational intervention, the mean scores and standard deviation of attitude $(25.94 \pm 5.95)$, subjective norm ( $37.22 \pm 7.31$ ), perceived behavioral control (34.80 \pm 5.42$)$, and behavior (26.86 $\pm 5.95)$, except for the behavioral intention $(14.02 \pm 3.11)$ in the test group, increased significantly $(p<0.001)$.

Conclusion: Based on the findings of this study, education based on planned behavior theory is fruitful and can improve students' microbial and mobile phone Preventive behaviors by increasing attitudes, subjective norm, and perceived behavioral control.

Keywords: Health Behavior, Cell Phone, Theory of Planned Behavior, Female, Students.

Paper Type: Research Article.

Citation (Vancouver): Savari Mombeni F, Babaei Heydarabadi A, Hatamzadeh $\mathrm{N}$, Sharhani A. Investigating the effect of educational intervention based on Theory of Planned Behavior on the preventive behaviors regarding microbial and radiation complications of mobile phone in female students of secondary school. Iran J Health Educ Health Promot. Summer 2021;9(2): 159-171.

- Citation (APA): Savari Mombeni F., Babaei Heydarabadi A., Hatamzadeh N., Sharhani A. (Summer 2021). Investigating the effect of educational intervention based on Theory of Planned Behavior on the preventive behaviors regarding microbial and radiation complications of mobile phone in female students of secondary school. Iranian Journal of Health Education \& Health Promotion., 9(2), 159-171. 


\section{تاثير مداخله آموزشى مبتنى بر نظريه رفتار برنامه ريزى شده در خصوص رفتارهاى بيشكيرانه \\ از عوارض ميكروبى و اشعه تلفن همراه در دانش آموزان دختر دوره متوسطه دوم دمونه}

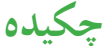

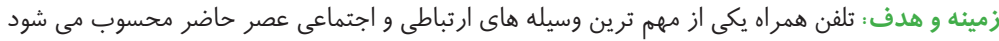

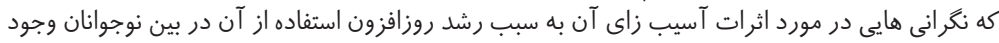

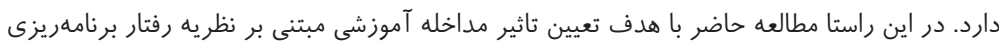

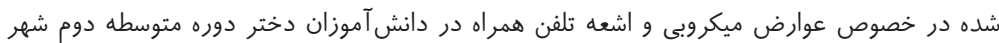
باغملك انجام شد.

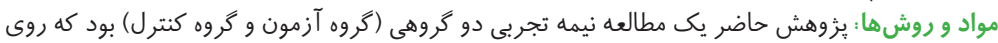

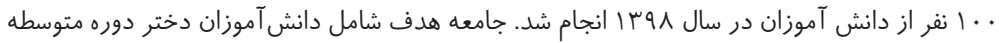

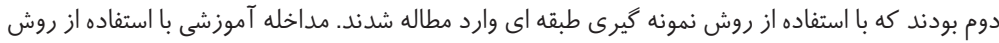

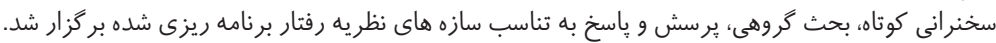

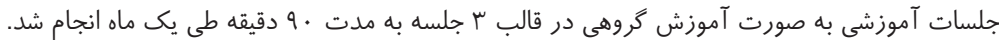

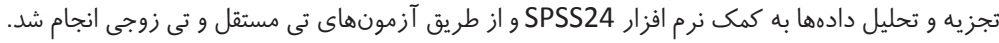

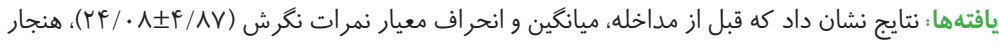
ذهنى (1) (

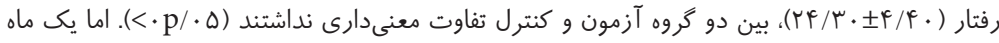

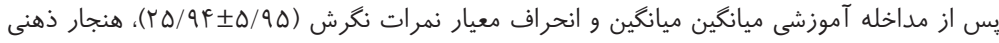

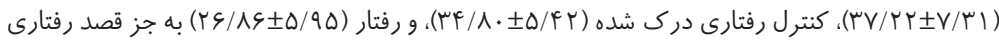

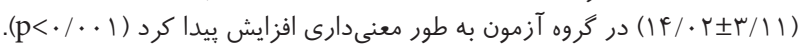

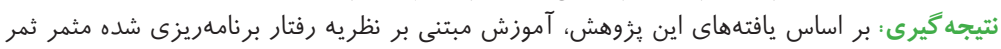

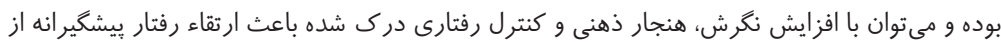

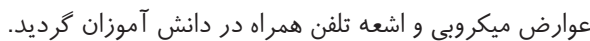

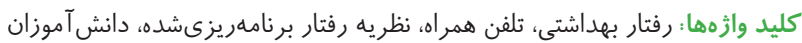
نوع مقاله : مطالعه : بزوهشى.

4

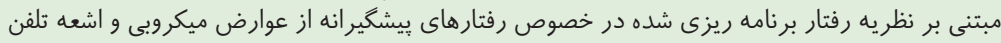

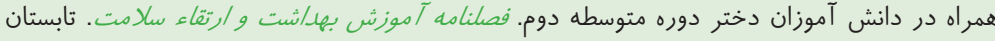
$.|\vee|-109:(Y) 9: 1 \uparrow \ldots$

4 استناد (APA): سوارى ممبنى، فاطمه؛ بابائى حيدر آبادى، اكبر ؛ حاتمزاده، ناصر ؛ شر هانى، اسعد. (تابستان

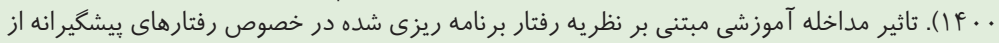

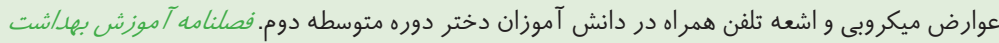

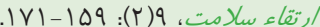

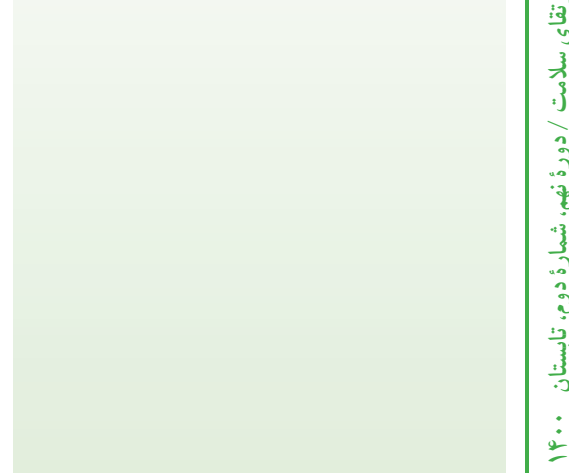

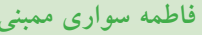
كارشناس ارشد آموزش بهداشت و و ارتقاء سلامت، مركز

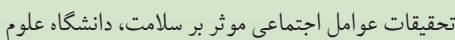
يزّشى جندى شايور اهواز، اهواز، ايران.

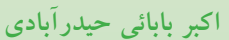

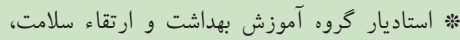

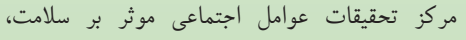

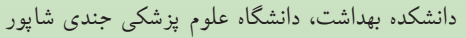

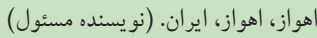
babaeinmz2056@gmail.com

ناصر حاتم زاده استاديار كروه آموزش بهداشت و واده ارتقاء سلامت، مركز

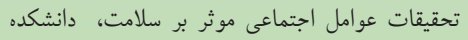

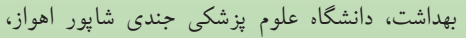
اهواز، ايران

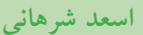
استاديار كروه آمار و إبيدميولوزىى، دانشكده بهداشت، دانشكاء علوم بزشكى جندى شايور اهواز، اهواز، ايران.

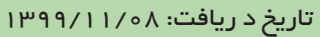

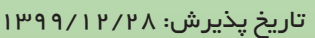


دوم نوع آلود گى را داشت (·r). در مطالعه سواد كوهى و همكاران

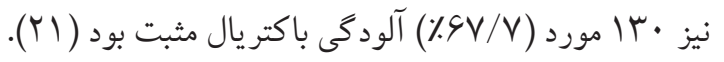

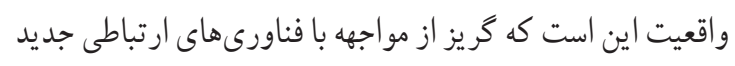

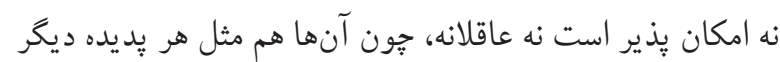

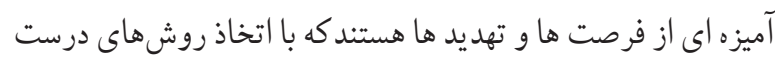

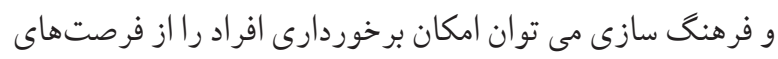

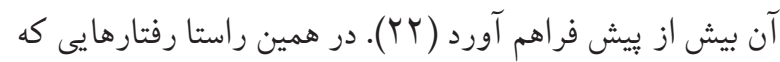
مى تواند در جهت بيشكيرى از عوارض ميكروبى و اشعه تلفن همراه

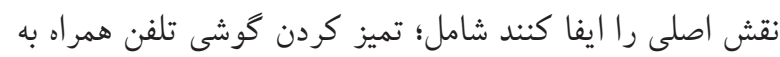
صورت روزانه، شستن دست قبل از خوردن غذا (در صورتى كه نهي

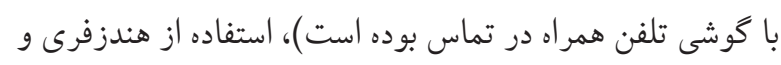

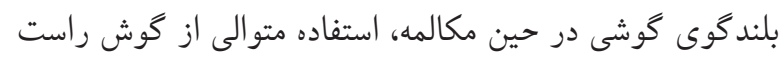

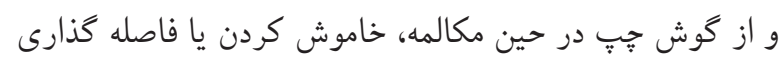
بين گوشى تلفن همراه با حداقل فاصله Y متر در هنكام خوابيدن، قرار ندادن گوشى تلفن همراه روى گوش بلاف بلافاصله بعد از شماره

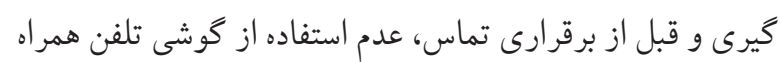
در حال شارز شدن و غيره مى باشد (· (19 19).

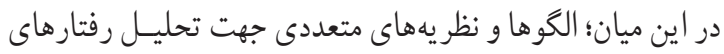
بهداشتى و هدايت مـداخلات آموزشسى وجود دارد (Tس (T) و نظريه رفتار برنامه ريزى شده يكى از نظريه هايى است كه داراى سازه هايى جون نكرش، هنجار ذهنى، كنترل رفتار درك شده و قصد سله

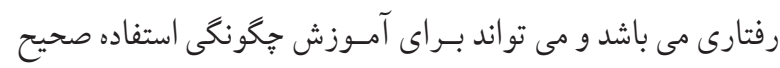

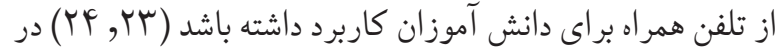
توجيه كاربرد اين نظريه مى توان بيان داشت كه اكثر رفتارهاى براي دان

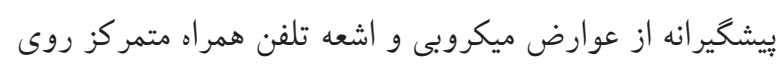
فرد مى باشد و نقش افراد و هنجارهاى ذهنى در اين خصوص تعيين

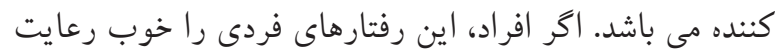
كنند مى تواند از بسيارى از آسيب هاى احتمالى مثل انتقال انواع

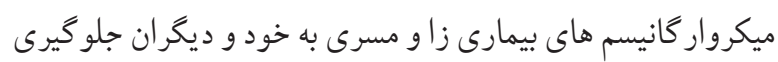

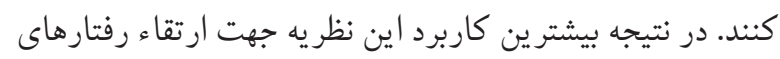

تلفن همراه يك از مهم ترين وسيله هاى ارتباطى و اجتماعى عصر حاضر محسوب مى شود كه در دسترس همكان قرار دارد ( ( و يكى از مهمترين مؤلفهاى فرهنكى نسل جوانان و نوجوانان به

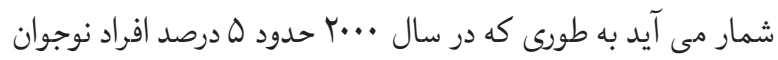
و جوان (Tا تا VI الهاله) تلفن همراه در اختيار داشتند اما هم اكنون

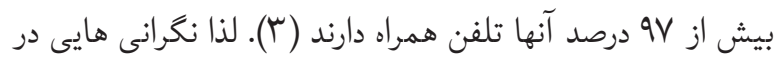
مورد اثرات مخرب تلفن هاى همراه به سبب رشد روزافزون استفاده از

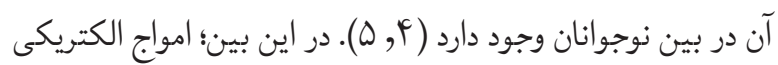

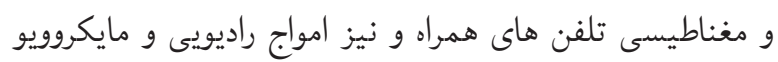

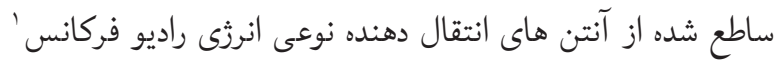
محسوب مىشوند (Y, (V) كه طبق نتايج مطالعات اين امواج تلفن همراه مى توانند باعث مشكلاتى از قبيل سردرد، احساس خستخى

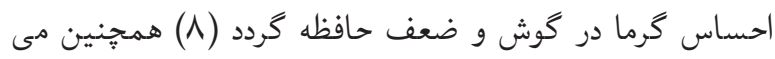

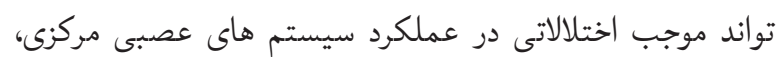
قلب-عروق، خونسازى، يوست و غيره گردد ( II). در همين راستا، نتايج مطالعات آزانس بين المللى سرطان نيز شواهدى مبنى بر بر بردي

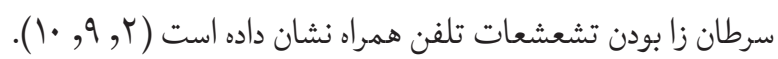

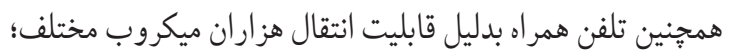

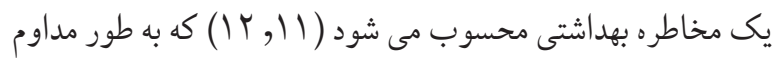
با دست و صورت در تماس مى باشد (r) و و بدين طريق مى تو اند

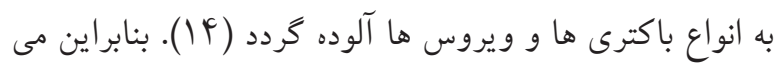
تواند به محلى براى رشد ميكروبها تبديل شود (ه (1). در همين خصوص، مطالعات متعددى وجود و رشد ميكروب ها را روى تلفن

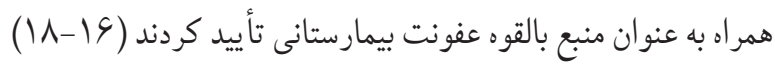

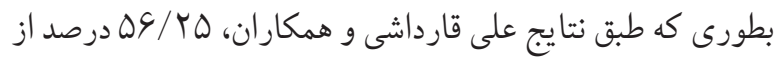

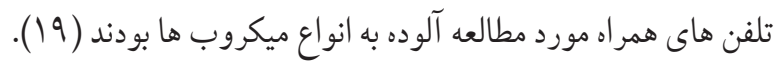

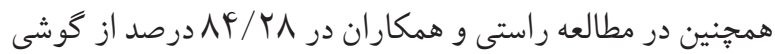

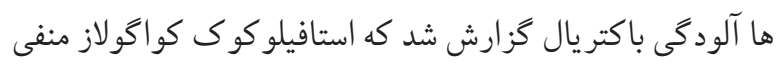

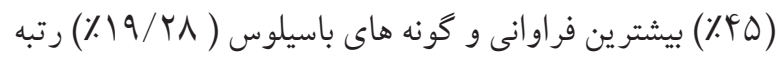


گروه كنترل نيز هر خايه تحصيلى •ا دانش آموز) و از دو مدرسه

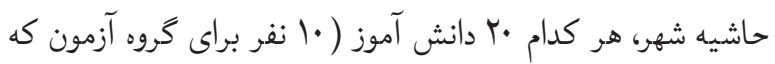

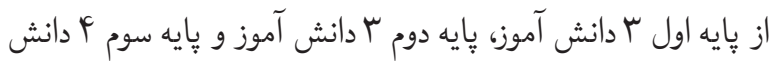

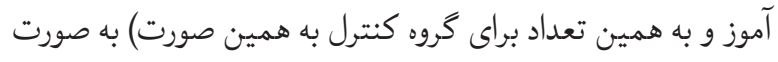
تصادفى انتخاب كرديد.

از آنجايى كه مطالعه اي كاملامشابه جهت تعيين حجم نمونه

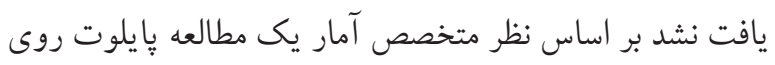

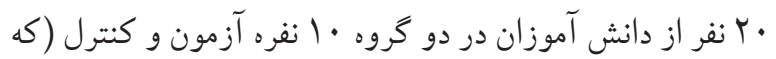
جز مطالعه نبودند) انجام شد و طبق نتايج، پِ از از بدست آوردن درن

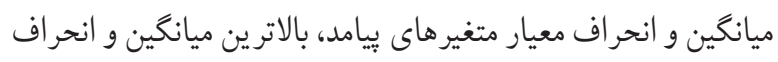

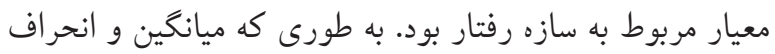

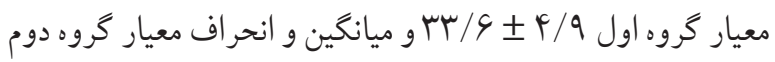
حُ

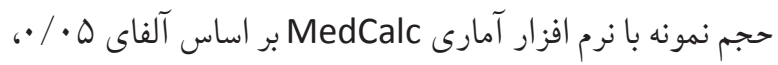

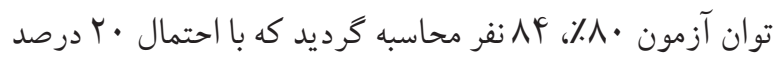

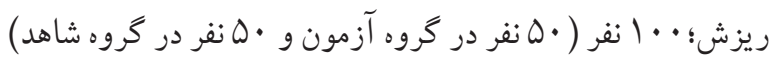

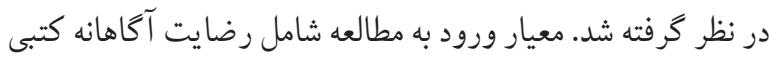

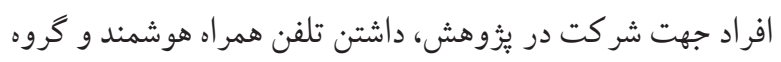

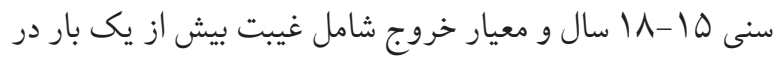

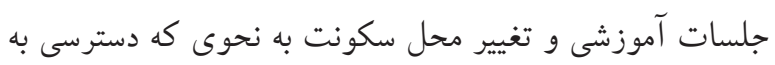
نمونه امكان يذير نباشد، بود. جهت مداخله آموزشى، در گروه آزمون اجراى برنامه آموزشى بودي

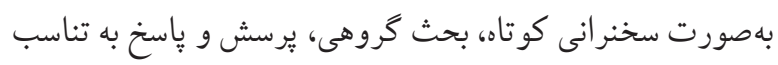

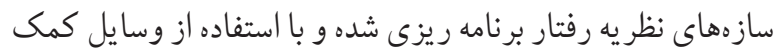
آموزشى مانند (يمفلت، نمايش كليب آموزشى) بر گزار شد. جلسات

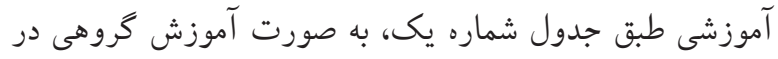

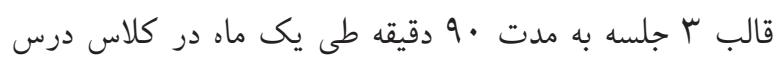

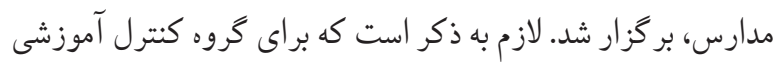

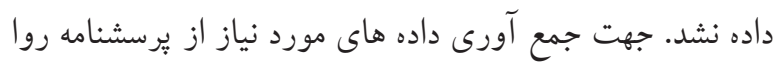

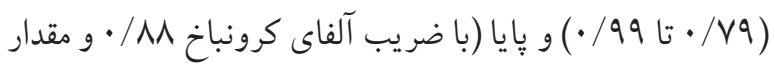

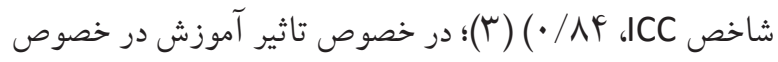

ارادى (رفتارهايى كه براى انجام شدن، تنها نيازمند اراده و تمايل

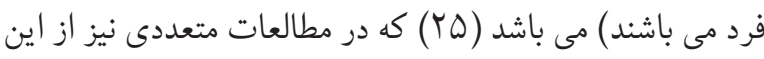

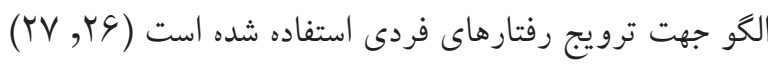
بنابر اين اين نظريه با تمر كز بر مطالعه نكخر شهاى افر اد؛ بر مهمتــرين

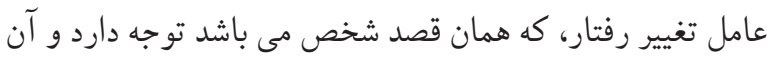

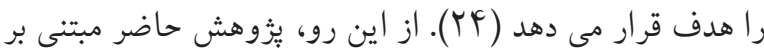

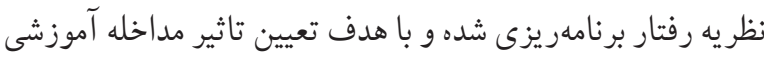
در خصوص رفتار هاى ييشكير انه از عوارض ميكروبى و اشعه تلفن همر اه در دانش آموزان دختر دوره متوسطه دوم شهر باغملك (استان خوزستان) انجام شد. مواد و ورش هاد يثوهش حاضر يك مطالعه نيمهتجربى از نوع مداخله آموزشى

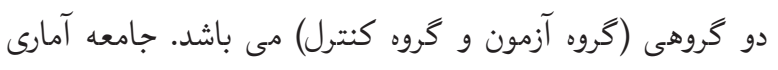
يُّوهش شامل كليه دانش آموزان دختر دوره متوسطه دوم منطقه شهرى باغملك بودند كه در سال تحصيلى

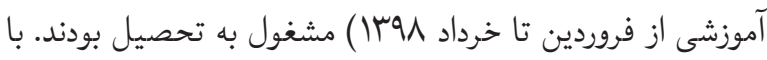

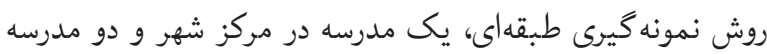

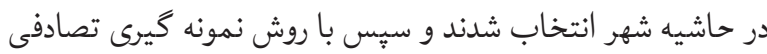
نمونه ها انتخاب شدند. لازم به ذكر است كه تعداد مدارس دخترانه دوره متوسطه دوم در شهرستان باغملك ه مدرسه مى باشد كه از نظر اجتماعى به بخش مركز شهر و حاشيه شهر تقسيم مى شود. براى اجراى روش نمونه گيرى طبقه اى، تنها مدرسه موجود در مركز

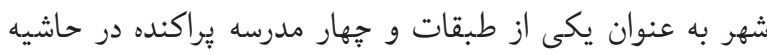

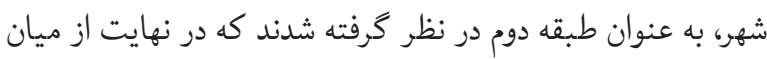

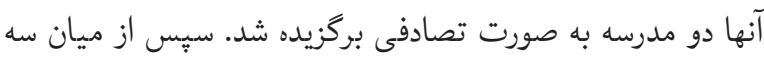

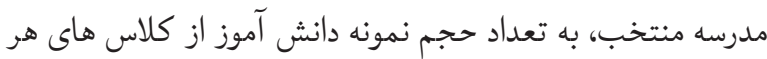
سه پايه به صورت تصادفى ساده (بر اساس فهرست هر كلاس) انتخاب شدند. بدين صورت كه از مدرسه مركز شهر به علت تعداد

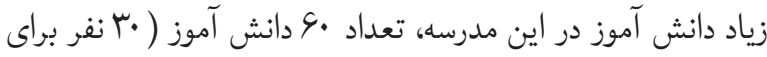

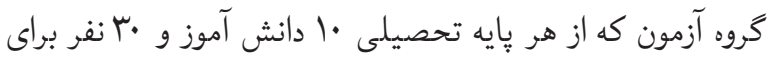


شد و نظرات اصلاحى آنها اعمال گرديد.

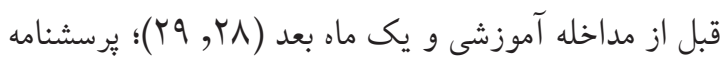
تحقيق توسط شر كت كنند كان تكميل شد. يرسشنامه هاى تكميل شده توسط محقق بهمنظور ثبت كامل آنها بررسى شد. داده هاى كمى موجود در برسشنامه كدگذارى گرديد و توسط نرم افزار SPSS(V20)

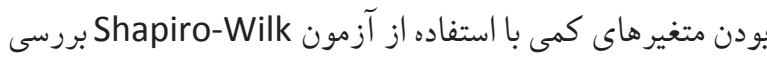
شد. در بخش آمار توصيفى از جدولهاى توزيع فراوانى، درصد

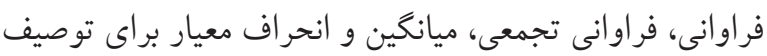

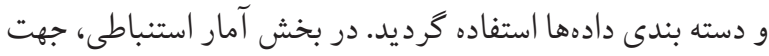

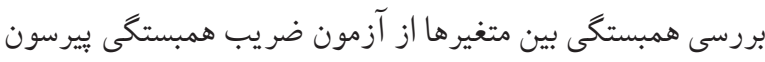

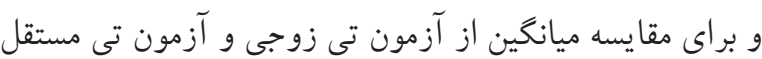

$$
\text { استفاده كرديد. (جدول شماره l) }
$$

كد اخلاق اين مطالعه به شماره IR.AJUMS.RES.1398.132 مى باشد و ملاحظات اخلاقى مطالعه شامل اخذ رضايت نامه آكاهانه از ياسخكو يان، اخذ مجوز مر اكز مربوطه، سعى در عدم ايجاد اختلال در انجام وظيفه مسئولين مدارس، توزيع بمفلت آموزشى براى گرُوه

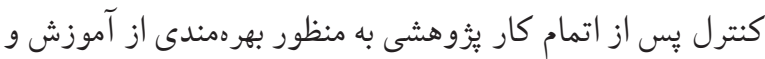
محرمانه ماندن اطلاعات دانش آموزان بود.

يافته ها دانش آموزان شركت كننده در اين مطالعه از نظر سنى بين سنين

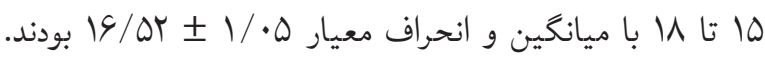

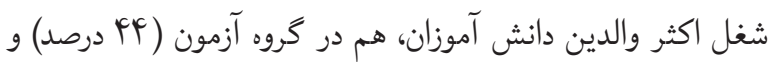

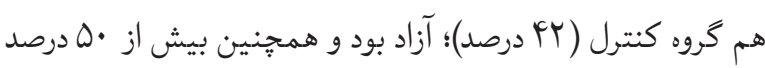
آنها داراى تحصيلات دبيرستان و دانشخاهى بودند. ميانكين ميزان

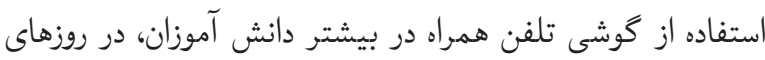
مدرسه، روزانه بين يك تا سه ساعت گزارش شد. (جدول شماره ؟)
رفتار بيشكيرانه از عوارض ميكروبى و اشعه تلفن همراه بر اساس

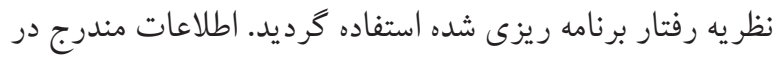

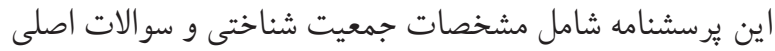
يُزوهش كه شامل بررسى وضعيت متغيرهاى نكرش (باورهاى رفتارى و ارزشيابى نتايج) 9 سوال (نمونه سوال: به نظر من استفاده

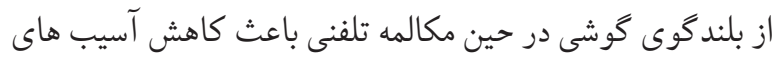

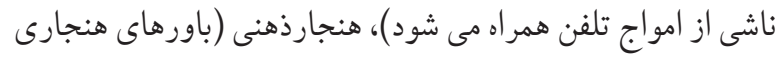

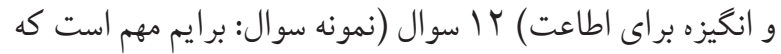

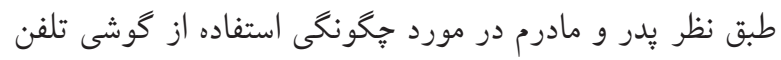

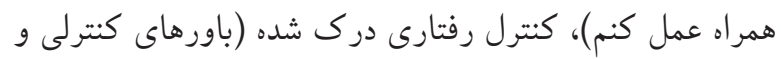

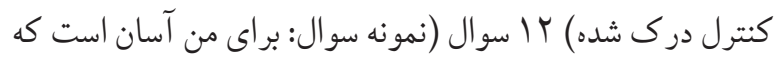

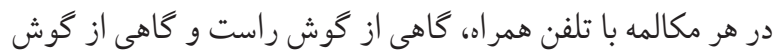

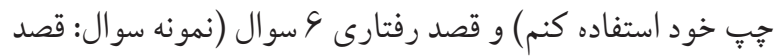
دارم گوشى تلفن همر اه خود را هر روز تميز كنم)، و رفتار 9 سوال

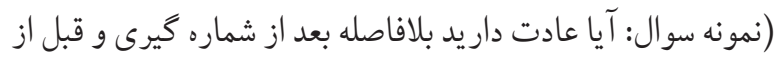
برقرارى تماس، گوشى تلفن همراه را روى گُش خود قرار دهيد؟)

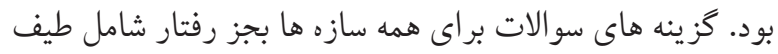

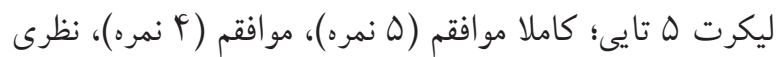

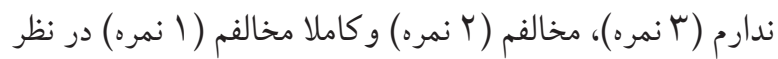

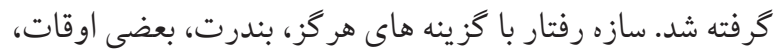
بيشتر اوقات و هميشه سنجيده شد. جهت طر احى محتوا آموزشى، با انجام بررسى اوليه در خصوص سمد

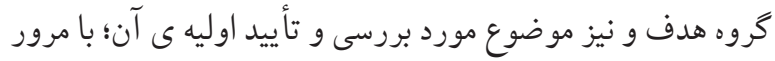

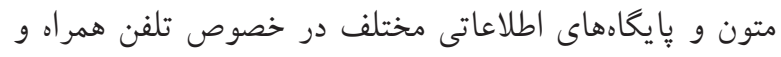

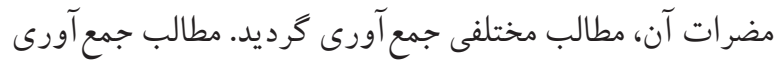

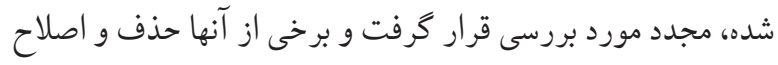

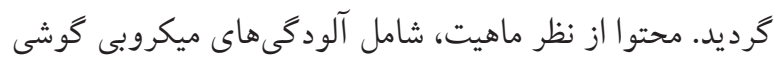

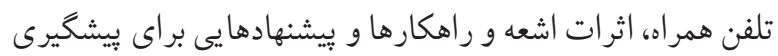
بود. براى اطمينان از اعتبار محتواى تهيه شده با متخصصان مختلف از جمله مهندسى بهداشت محيط (ا نفر)، مهندسى بهداشت حرفه

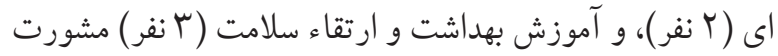


جدول ا. جزئيات برنامه جهت اجراى مداخله آموزشى

\begin{tabular}{|c|c|c|c|c|}
\hline روش آموزش & سازه & محتواى آموزش & هدف & جلسه \\
\hline 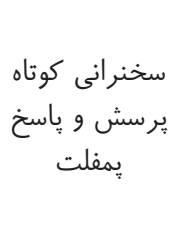 & و كنترش، هنجار ذهنى رفتارى & 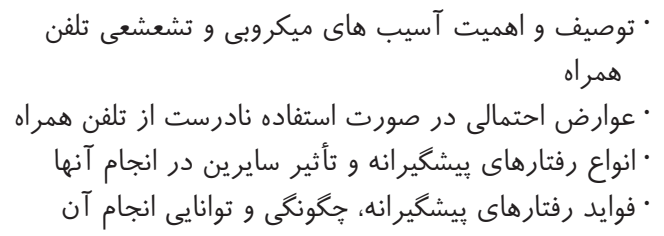 & 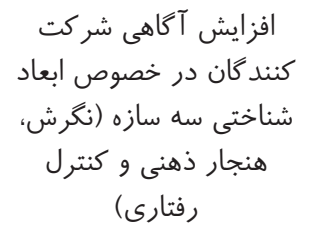 & اول \\
\hline كليب آموزشى گروهى & نغرش و قصد & 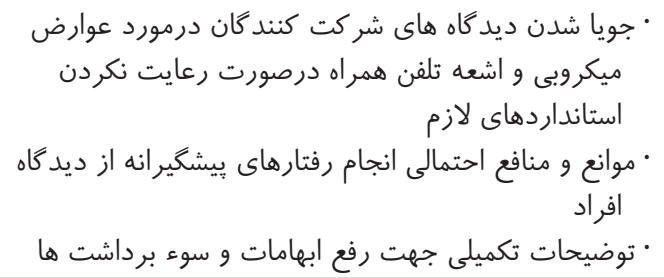 & 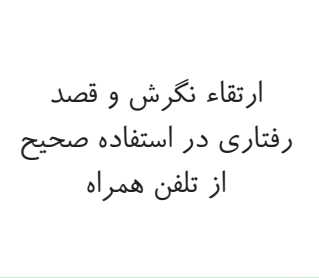 & دوم \\
\hline برسث و گروهى & درك شده، رفتارى & 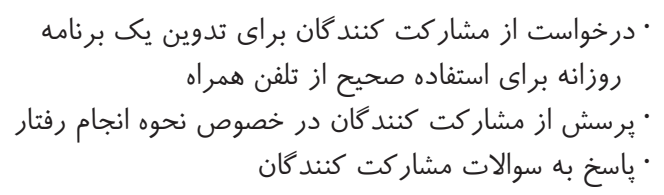 & 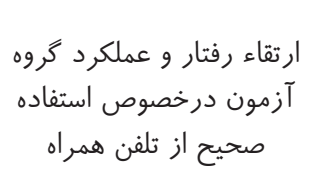 & سوم \\
\hline
\end{tabular}

\begin{tabular}{|c|c|c|c|c|c|}
\hline \multirow{2}{*}{ سآزمون معنادارى } & \multicolumn{2}{|c|}{ كنترل } & \multicolumn{2}{|c|}{ آزمون } & \multirow{2}{*}{ سن دانش آموز } \\
\hline & درصد & تعداد & درصد & تعداد & \\
\hline \multirow{4}{*}{. } & $1 \cdot /$ & $\Delta$ & 1. & $\Delta$ & ها سال \\
\hline & $\mu F /$ & IV & rs & ir & 19 ال سال \\
\hline & $\varphi \& /$. & $r \mu$ & $\mu q$ & IV & IV \\
\hline & $1 . \%$ & 0 & $r$. & 10 & 11 1 سال \\
\hline \multirow{4}{*}{$\cdot / r F$} & \multicolumn{5}{|c|}{ شغل پدر } \\
\hline & $\varphi \cdot /$ & $r$. & rᄉ & 19 & كارمند \\
\hline & $\mathrm{Fr} /$. & rl & pq & rr & آزاد \\
\hline & $1 N /$ & 9 & 11 & 9 & كشاورز \\
\hline \multirow{3}{*}{.$/ 91$} & \multicolumn{5}{|c|}{ شغل مادر } \\
\hline & 11 & 9 & 11 & 9 & غير خانه دار \\
\hline & $\Delta r$ & $q_{1}$ & $\Delta r$ & +1 & خانه دار \\
\hline \multirow{5}{*}{.$/ 9 F$} & \multicolumn{5}{|c|}{ تحصيلات يدر } \\
\hline & s/. & r & if & v & بى سواد \\
\hline & rr & 19 & rF & ir & ابتدايى و راهنمايى \\
\hline & $\mu r /$. & 19 & rr & 11 & دبيرستان \\
\hline & $\mu . /$. & 10 & r. & $r$. & دانشكاهى \\
\hline
\end{tabular}




\begin{tabular}{|c|c|c|c|c|c|}
\hline \multirow{5}{*}{$\cdot / \Delta V$} & \multicolumn{5}{|c|}{ تحصيلات مادر } \\
\hline & $r / \cdot$ & 1 & r & 1 & بى سواد \\
\hline & pr & rt & r & 19 & ابتدايى و راهنمايى \\
\hline & $\mu F /$. & IV & rF & Ir & دبير ستان \\
\hline & $r \cdot / \cdot$ & 1. & $r F$ & ir & دانشگاهى \\
\hline \multirow{6}{*}{$\cdot / \mathscr{G V}$} & \multicolumn{5}{|c|}{ ميزان استفاده روزانه } \\
\hline & rN/. & if & r. & 10 & كمتر از يك ساعت \\
\hline & $r r / \cdot$ & 19 & r & 19 & بين يك تا سه ساعت \\
\hline & $\mid N / \cdot$ & 9 & $r$ & 1. & بين سه تا ينج ساعت \\
\hline & $r r / \cdot$ & 11 & ir & 4 & بيشتر از ينج ساعت \\
\hline & $1 \ldots$ & $\Delta$. & $1 \cdots$ & $\Delta$. & جمع \\
\hline
\end{tabular}

جهت تعيين رابطه بي بين متغير هاى بُزوهش، از آزمون همبستكى دارى با نكُش، هنجار ذهنى و كنترل رفتارى درى شده دارد. به طور

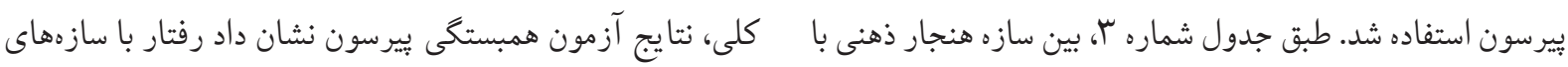

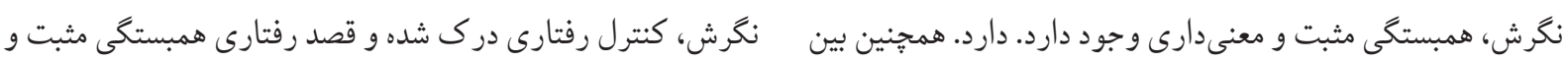

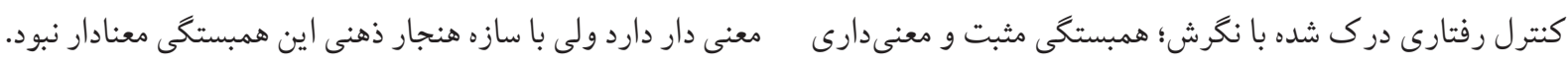

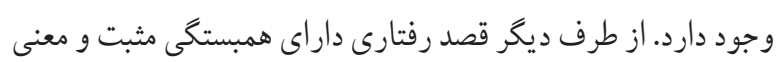

جدول س. ضريب همبستخى ييرسون متغيرهاى تحقيق

\begin{tabular}{|c|c|c|c|c|c|}
\hline 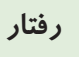 & قصد رفتارى & كنترل رفتارى & هنجار ذهنى & 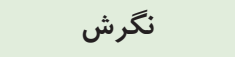 & متغير \\
\hline & & & & 1 & 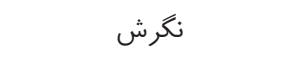 \\
\hline & & & 1 & $\cdot / \operatorname{er}(P=\cdot / \cdot 1)$ & هنجار ذهنى \\
\hline & & 1 & $\cdot / \cdot \wedge(P=\cdot / \mathbb{F} r)$ & $\cdot / \mu_{1}(\mathrm{P}=\cdot / \cdot r)$ & كنترل رفتارى درى شده \\
\hline & & $\cdot / \mu \cdot(P=\cdot / \cdot \mu)$ & $\cdot / \operatorname{Fr}(P=\cdot / \cdot \operatorname{l})$ & $\cdot / 01(P=\cdot / \cdot 1)$ & قصد رفتارى \\
\hline 1 & $\cdot / 01(P=\cdot / \ldots 1)$ & $\cdot / \Delta 9(P=\cdot / \cdot 1)$ & $\cdot / r \cdot(P=\cdot / 01)$ & $\cdot / \mu \Delta(P=\cdot / \cdot r)$ & رفتار \\
\hline
\end{tabular}

با توجه به نتايج جدول شماره f قبل از مداخله ميانگين و أل، قبل از مداخله آموزشى، ميانگين نمره هنجارهاى ذهنى، كنترل

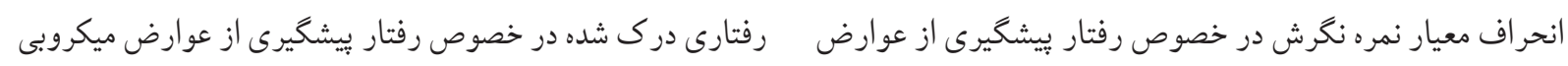

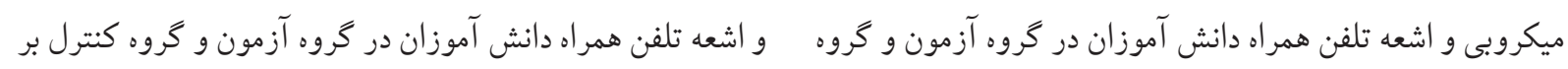

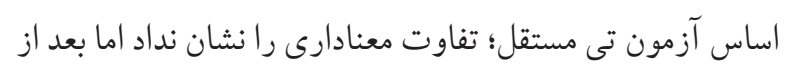
كنترل به ترتيب M

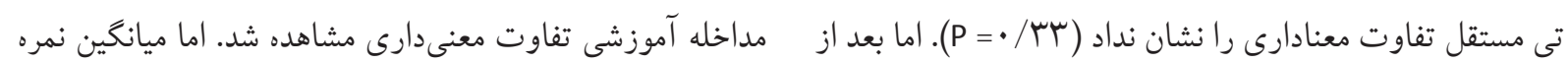

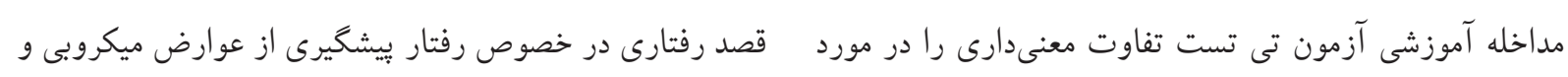

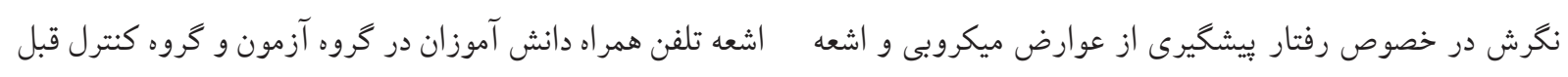

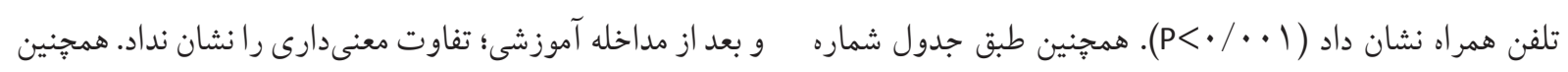


ميانكين و انحر اف معيار نمره رفتار بيشخيرى از عوارض ميكروبى از مداخله آموزشى آزمون تى تست تفاوت معنىدارى رادر مورد

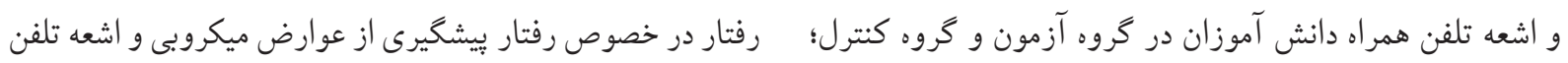

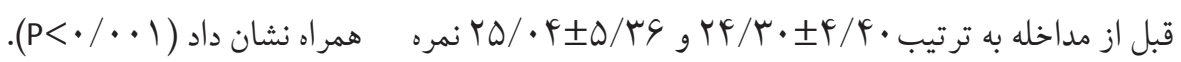

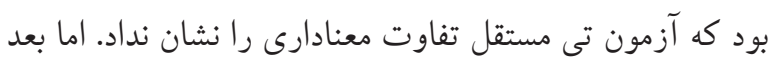
جدول عا. مقايسه ميانكَين و انحراف معيار نمره سازه هاى نظريه رفتار برنامه ريزى شده، قبل و بعد از مداخله به تفكيى كَروههاى آزمون و كنترل

\begin{tabular}{|c|c|c|c|c|}
\hline \multirow{2}{*}{ P.value ${ }^{*}$} & بعد مداخله & قبل از مداخله & \multirow[b]{2}{*}{ كروه } & \multirow{2}{*}{ متغير } \\
\hline & انحراف معيار \ميانگين & انحراف معيار \ميانكين & & \\
\hline$\cdot / \cdot r \cdot$ & $r \Delta / ৭ q \pm \Delta / ৭ \Delta$ & $r F / \cdot \Lambda \pm r / \Lambda V$ & آزمون ( • (n=0) & \multirow{3}{*}{ نغرش } \\
\hline \multirow[t]{2}{*}{.190} & $r r / q \cdot \pm r / v q$ & $r \mu / \mu \cdot \pm r / v s$ & كنترل (n=0) & \\
\hline & $\cdot / \cdot r$ & س זس/. & $* *$ Pvalue & \\
\hline$\cdot / \cdots$ & $r V / r r \pm V / \widetilde{I}$ & $r Y / \Delta r \pm V / S V$ & آزمون ( • (n=0) & \multirow{3}{*}{ هنجار ذهنى } \\
\hline \multirow[t]{2}{*}{$\cdot / \varepsilon \mu$} & $r \mu / V \Delta \pm V / 11$ & $\mu r / r \cdot \pm V / r \Lambda$ & كنترل (n=0) & \\
\hline & $\cdot / \cdots$ &.$/ 9 \mu$ & $* *$ Pvalue & \\
\hline.$/ \cdot 1$ & $\mu F / \Lambda \cdot \pm \Delta / \mathcal{F}$ & $\Gamma r / r \Lambda \pm \Delta / \cdot \Delta$ & آزمون ( • (n=ه) & \multirow{3}{*}{ درك شدر رفتارى } \\
\hline \multirow[t]{2}{*}{.$/ 0 r$} & $r r / G V \pm S / r r$ & $r r / F \cdot \pm s / F \Delta$ & كنترل ( • (n=0) & \\
\hline & $\cdot / \mu^{\mu}$ & $\cdot / 0 r$ & $* *$ Pvalue & \\
\hline.$/ 9 r$ & $\mid r / \Psi \wedge \pm \mu / q \vee$ & $|r /| f \pm F / f q$ & آزمون ( • (n=ه) & \multirow{3}{*}{ قصد رفتارى } \\
\hline$\cdot / r \wedge$ & $|F / \cdot r \pm r /| \mid$ & $\mid r / V F \pm r / \Delta s$ & كنترل ( • (n=0) & \\
\hline &.$/ 19$ & $\cdot|\wedge|$ & **Pvalue & \\
\hline.$/ \cdot 11$ & $r \varepsilon / \wedge \varepsilon \pm \Delta / ৭ \Delta$ & $r F / \mu \cdot \pm r / F$. & آزمون ( • (n=ه) & \\
\hline \multirow[t]{2}{*}{$\cdot / D F$} & $r \Delta / G Y \pm \Delta / r r$ & $r \Delta / \cdot r \pm \Delta / r s$ & كنترل ( • (n=0) & رفتار \\
\hline &.$/ \cdot 1$ & $\cdot|4|$ & $* *$ Pvalue & \\
\hline
\end{tabular}

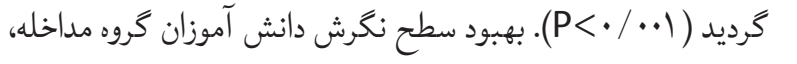
نشان دهنده ى اثربخشى مداخلهى آموزشى در تغيير نكرش است.

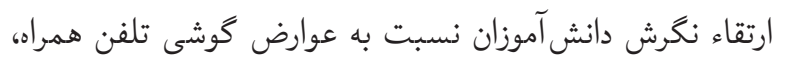
مى تواند تاثير شايان توجهى در كرايش آنان به استفاده صحيح از

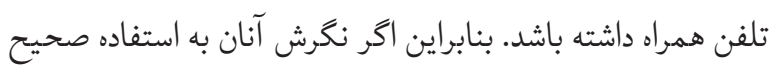
از تلفن همراه مثبت باشد و اين كار را مفيد و سودمند بدانند اين 
خواهر و برادر در انتخاب شيوه زندگى مؤثر بوده و مى تواند باعث افزايش توانايى آنها در تغيير رفتار شود.

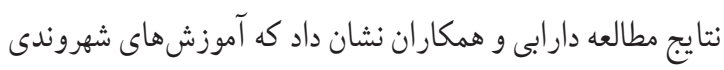

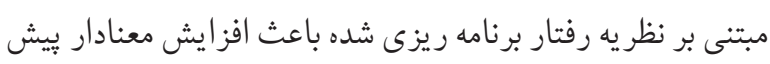

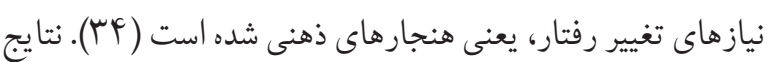

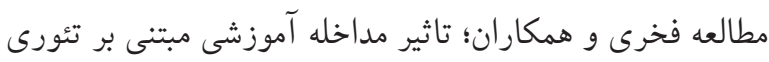

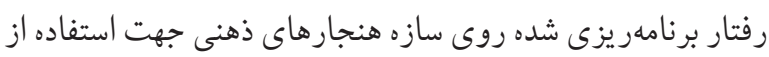

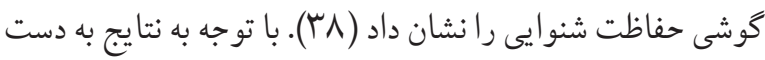
آمده از تحقيقات مى توان اظهار كرد محيط حمايت كننده در تغيير

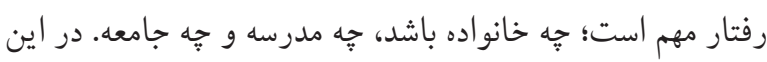

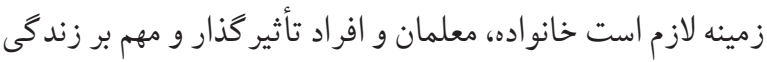

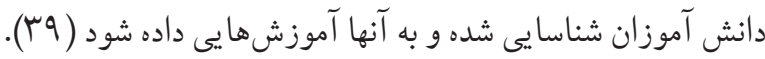
سومين سازه اصلى نظر يه رفتار برنامهريزى شده، كنترل رفتار

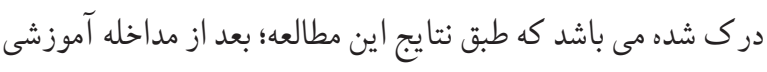

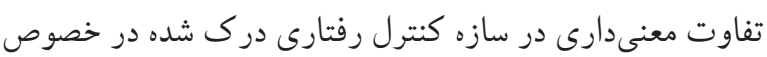
رفتار بيشخيرى از عوارض ميكروبى و اشعه تلفن همراه مشاهده

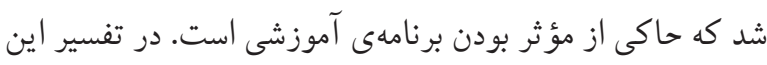

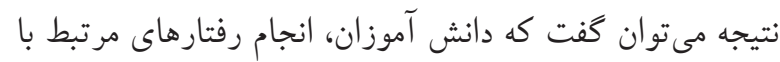

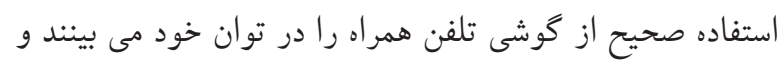
رفتارهاى كنترلى لازم براى استفاده صحيح از گوشى تلفن همراه

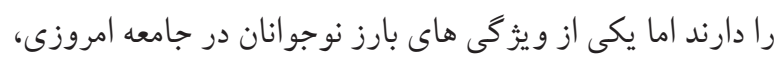

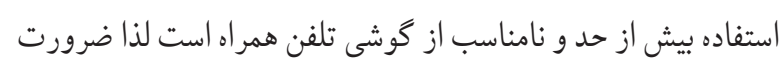
دارد در برنامههاى آموزشى مستقيم و غير مستقيم اهميت استفاده صحيح از گوشى تلفن همراه مدنظر واقع شود. به طور كلى نتايج اين مطالعه، در خصوص تأثير مداخله آموزشى روى سازه كنترل

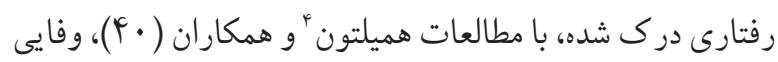

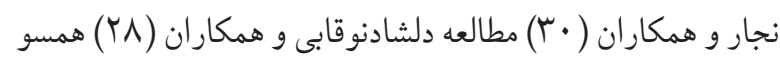
بود. بنابراين مىتوان اظهار داشت اخر فرد عقيده داشته باشد كه ونه

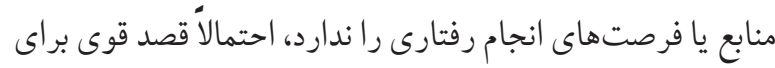

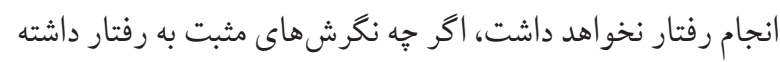

4. Hamilton
عمل براى آنان رضايت بخش بوده و آن را با ارزش تلقى مى كنند.

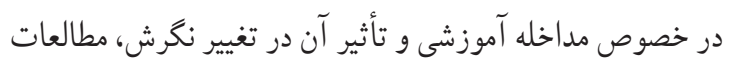
كوناگونى انجام شده است از جمله در نتايج مطالعه وفايى نجار و و همكاران كه با هدف تعيين قدرت بيش بينى كنند

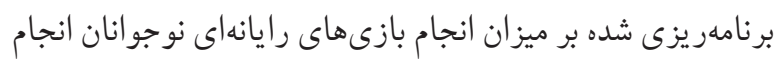

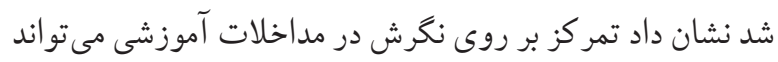

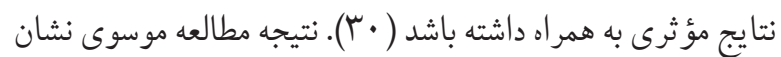

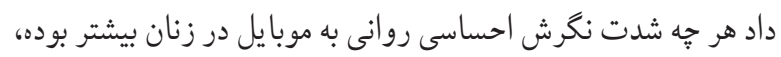

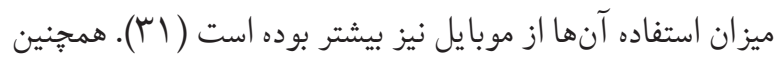
در مطالعه سولمان' و همكاران بر تأثير سازه نكرش بر رفتار استفاده

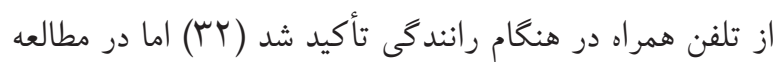

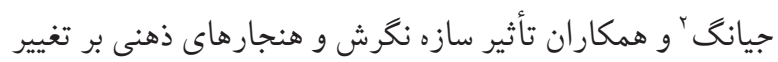
رفتار استفاده از تلفن همراه هنكام دوجرخه سو ارى؛ برخلاف سازه

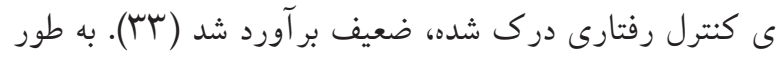

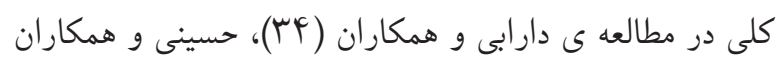

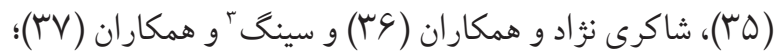

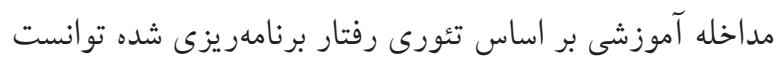
باعت ارتقاء سازه نكرش شود. دومين سازه نظريه رفتار برنامهريزى شده هنجار ذهنى است سترداء

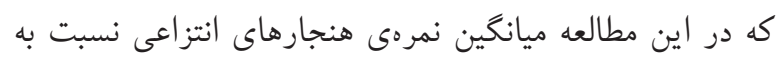

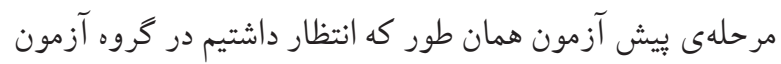

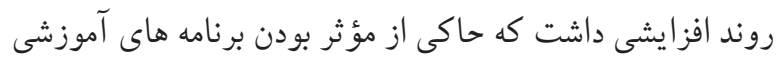

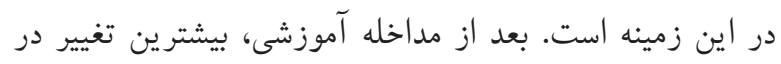

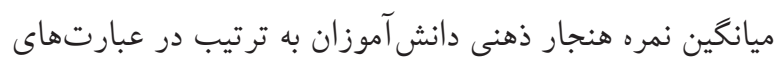
(ابراى همكلاسى هاى من مهم است كه جخحونه از گوشى تلفن همراه استفاده مى كنم)" و ((برايم مهم است كه طبق نظر خو هماهر و و برادرم

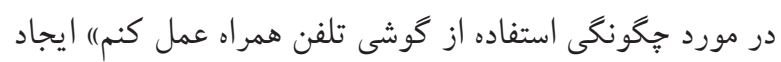
شد. در بيان دلايل اين مهم؛ مىتوان به تاثير يذيرى دانش آموزان هوران

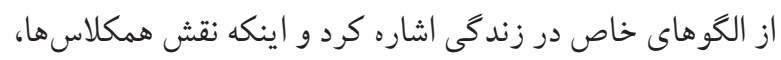


از محدوديت هاى اين يُزوهش مى توان به مواردى مثل دخالت

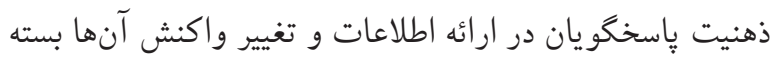
به شرايط محيطى و زمانى با توجه به نيمه تجربى بودن مطالعه،

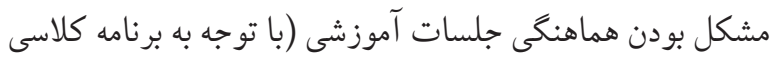

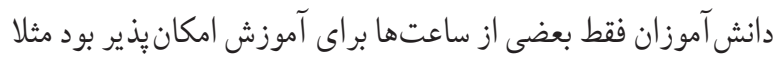

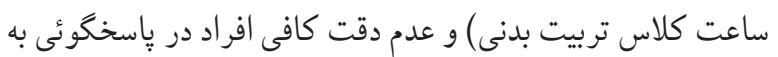

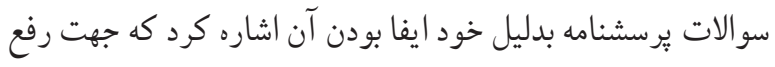

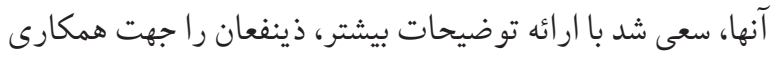
بهتر، قانع كرد و انعطاف لازم را متناسب با شر ايط مدرسه، جهت

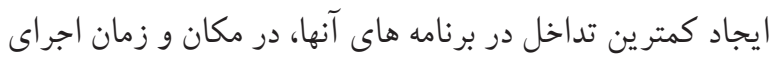
مداخله آموزشى لحاظ كرد.

$$
\text { نتيجه كيرى مداخله }
$$

با توجه به استفاده بسيار زياد نوجوانان و به ويثه دانش آموزان از تلفن همراه در ساعات مختلف شبانه روز، توجه به رفتارهاى بيشخيرانه از عوارض ميكروبى و اشعه گوشى تلفن همراه در اين قشر، مداخلات

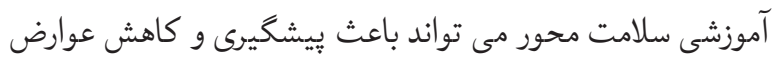

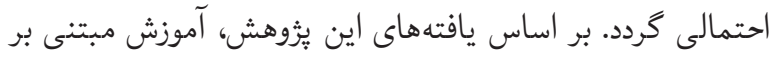

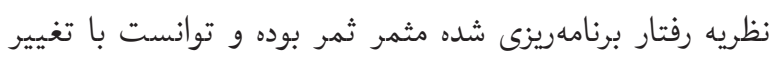
نكرش، هنجار ذهنى و كنترل رفتارى درك شده باعث ارتقاء رفتار ييشخيرانه از عوارض ميكروبى و اشعه تلفن همراه در دانش آموزان

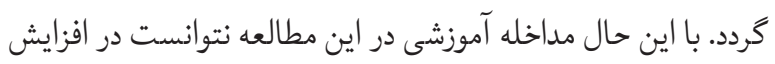
ميانكين نمرات همه سازههاى مربوطه موفق باشد.

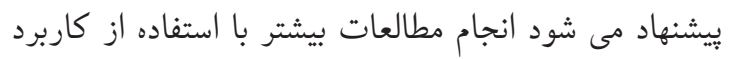

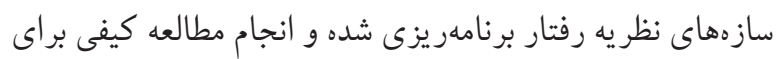

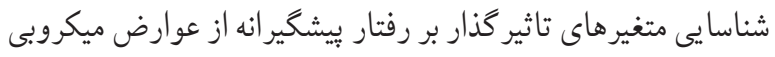

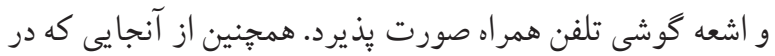
مطالعه حاضر، تمر كز تيم تحقيق بر عوارض ميكروبى و تشعشعى لته

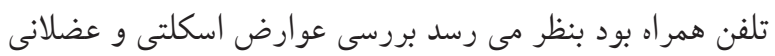
تلفن همر اه نيز مى تواند مفيد واقع شد.

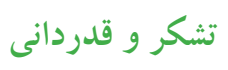

اين مقاله منتج از پايان نامه كارشناسى ارشد آموزش بهداشت و
باشد و حتى عقيده داشته باشد كه افر اد مهم هم آن رفتار را تصويب

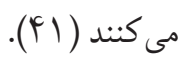

سازه ى بعدى نظريه رفتار برنامهريزى شده قصد رفتارى مى باشد كه در اين مطالعه طبق نتايج آزمون تى تست، بعد از مداخله

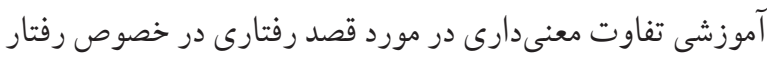

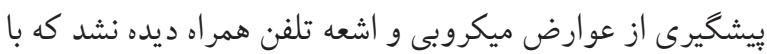

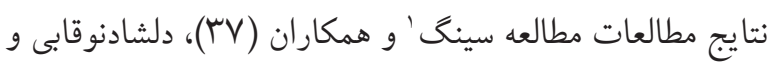

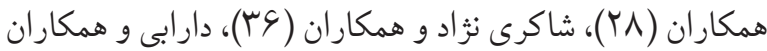

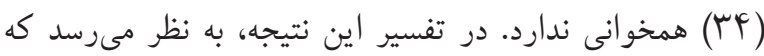

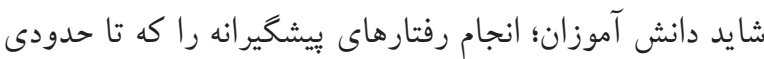

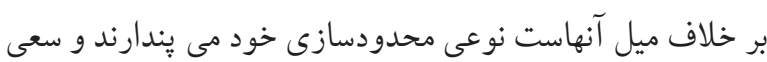

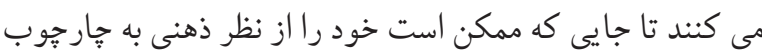

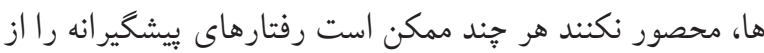

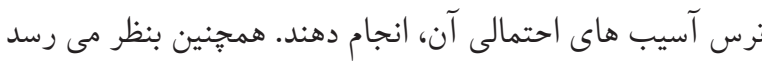

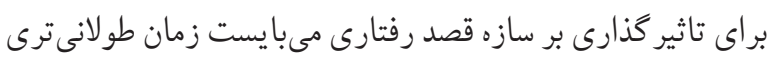

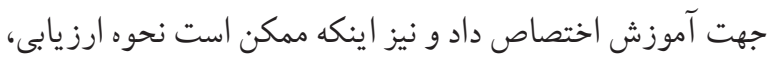

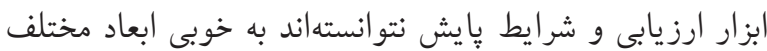
متغير مورد نظر را مورد سنجش قرار دهد.

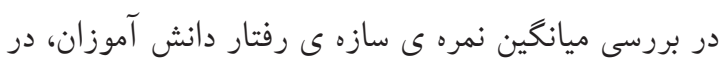
خصوص اقدامات بيشخيرانه از عوارض ميكروبى و اشعه تلفن همراه؛ نتايج آزمون تى تست بعد از مداخله آموزشى معنى دارى شد كه بهبود

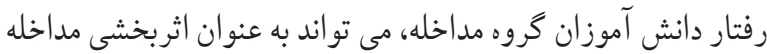

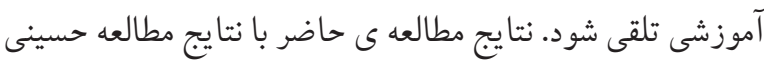

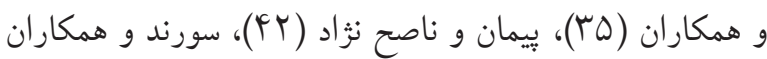

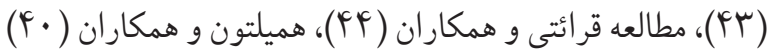

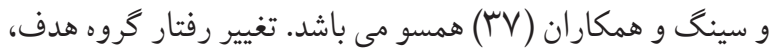
يكى از مهمتر ين دستاوردهاى هر مداخله آموزشى تلقى مى شد.

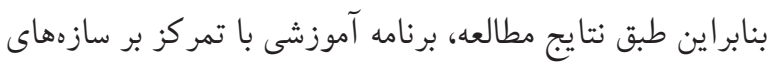

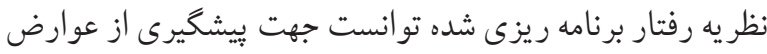

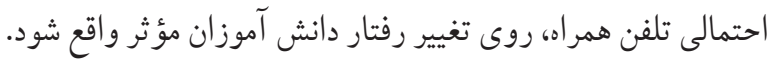




$$
\begin{aligned}
& \text { نمودند قدردانى به عمل مى آيد. } \\
& \text { تعارض در منافع } \\
& \text { نويسندگان اظهار مىدارند هيج گونه تعارض منافعى در مورد اين }
\end{aligned}
$$

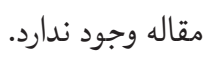

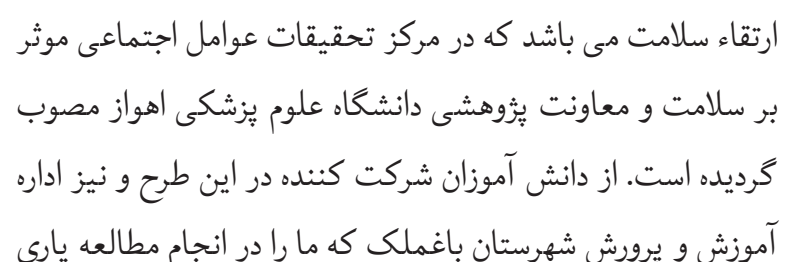

\section{References}

1. Hou M, Cheng J. The Role of Social Networks in Mobile Phone Use among Pedestrians: A Pilot Study in China. Sustainability. 2021;13(1):420. https://doi.org/10.3390/su13010420

2. Ebrahimi F, Aghamolaei T, Abedini S, Rafati $S$. Effect of Educational Intervention Using Mobile on Life Style of Women Who Referred to Health Centers in Bandar Abbas. Iranian Journal of Health Education and Health Promotion. 2017;5(2):81-9. https://doi.org/10.30699/acadpub.ijhehp.5.2.81

3. Mombeni FS, Heidarabadi $A B$, Hatamzadeh $N$, sharhani A. Designing Theory of Planned Behavior questionnaire and evaluation of its validity-reliability in order to assess the preventive behavior of mobile phone usage in girl students. Journal of Health in the Field. 2020;8(1):13-21.

4. Nazari E, Asgari P, Aghemiri M, Shahriari MH, Zangeneh A, Tabesh H. Developing a Questionnaire for Mobile Phone Usage Pattern Among University Students Using the Delphi Method. Frontiers in Health Informatics. 2021;10(1):52. https://doi.org/10.30699/fhi.v10i1.241

5. Goswami V, Singh DR. Impact of mobile phone addiction on adolescent's life: A literature review. Int J Home Sci. 2016;2(1):69-74.

6. Birks LE, van Wel L, Liorni I, Pierotti L, Guxens M, Huss $A$, et al. Radiofrequency electromagnetic fields from mobile communication: Description of modeled dose in brain regions and the body in European children and adolescents. Environmental Research. 2020;193:110505. https://doi.org/10.1016/j.envres.2020.110505 PMid:33245886

7. Besset A, Espa F, Dauvilliers Y, Billiard M, De Seze RJBJotBS, The Society for Physical Regulation in Biology, Medicine TEBA. No effect on cognitive function from daily mobile phone use. 2005;26(2):102-8. https://doi org/10.1002/be m. 20053 PMid:15672372

8. Yioultsis T, Kosmanis T, Kosmidou E, Zygiridis T, Kantartzis N, Xenos $T$, et al. A comparative study of the biological effects of various mobile phone and wireless LAN antennas. IEEE transactions on magnetics. 2002;38(2):777-80. https://doi.org/10.1109/20.996201

9. Mohammadi Seif $M$, Aref M. Cell Phone: its Biological threats and Consequences among Teenagers. Journal of
Islam and Social Studies. 2015;3(9):155-94.

10. Heydarabadi AB, Ramezankhani A, Ghaffari M, Mehrabi $Y$, Zare S. How do the staffs working in steel factories in Ardekan City deal with the risks of mobile phones? 2016.

11. Bodena D, Teklemariam Z, Balakrishnan S, Tesfa T. Bacterial contamination of mobile phones of health professionals in EasternEthiopia:antimicrobialsusceptibilityandassociated factors. Tropical medicine and health. 2019;47(1):1-10. https://doi.org/10.1186/s41182-019-0144-y PMid:30858754 PMCid:PMC6391816

12. ch'abi Ali (2014). Determining the Rate and Type of Bacterial Contamination of Mobile Phones of Ahwaz Dentists Specialists in 2014, Thesis for Ph.D. in Dentistry, Ahwaz Jundishapur University of Medical Sciences and Health Services (in Persian).

13. Akinyemi KO, Atapu AD, Adetona OO, Coker AO. The potential role of mobile phones in the spread of bacterial infections. The Journal of Infection in Developing Countries. 2009;3(08):628-32. h tt p s: / / d o i.org/10.3855/jid c. 556 PMid:19801807

14. Tambekar D, Gulhane P, Dahikar S, Dudhane M. Nosocomial hazards of doctor's mobile phones in hospitals. J Med Sci. 2008;8(1):73-6. https://doi.org/10.3923/jms.2008.73.76

15. Pal S, Juyal D, Adekhandi S, Sharma M, Prakash $\mathrm{R}$, Sharma $\mathrm{N}$, et al. Mobile phones: Reservoirs for the transmission of nosocomial pathogens. Advanced biomedical research. 2015;4. https://doi.org/10.4103/2277-9175.161553 PMid:26322292 PMCid:PMC4549928

16. Ramezankhani A, Ghaffari M, Mehrabi Y, Kashfi SH, Babaei Heydarabadi A. The Educational Intervention on People's Behavior in terms of the Microbial Contaminations of Mobile Phones and the Possible Adverse Effects 2016;4(12):3977-87.

17. Araya S, Desta K, Woldeamanuel Y. Extended-Spectrum Beta-Lactamase-Producing Gram-Negative Bacteria on Healthcare Workers' Mobile Phones: Evidence from Tikur Anbessa Specialized Hospital, Addis Ababa, Ethiopia. Risk Management and Healthcare Policy. 2021;14:283. https://doi.org/10.2147/R MHP.S291876 of their Beam. International Journal of Pediatrics. 


\section{PMid:33531847 PMCid:PMC7847411}

18. Mushabati NA, Samutela MT, Yamba K, Ngulube J, Nakazwe R, Nkhoma $P$, et al. Bacterial Contamination of Mobile Phones of Healthcare Workers at the University Teaching Hospital, Lusaka, Zambia. Infection Prevention in Practice. 2021:100126. https://doi.org/10.1016/j.infpip.2021.100126

19. Alighardashi M, Aeini M, Aeinian F, Mohamadi H. The Amount and Type of Microbial Contamination on Cell Phones of Medical Staff in Shahid Beheshti Hospital, Hamadan, Iran. Journal of Health System Research. 2012;7(6):533-.

20. Rasti F, Asghari E, Shahsavarinia K, Motazedi Z, Dehgani L. Microbial contamination of health care workers' mobile phones in Sina hospital, Tabriz. Hayat. 2016;22(2):128-37.

21. Barari Sawadkohi R, Pornasrollah M, Rajabnia R, Salar $\mathrm{N}$, Bijani A, Mirzapour M. Comparison of the Microbial Colonization of Mobile Phone between Health Care Personnel and Non-Care Personnel of Babol University of Medical Science Hospitals. Journal of Babol University Of Medical Sciences. 2014;16(5):67-71.

22. Raja R, Nagasubramani P. Impact of modern technology in education. Journal of Applied and Advanced Research. 2018;3(1):33-5. https://doi.org/10.21839/jaar.2018.v3iS1.165

23. Alami A, Tavakoly Sany SB, Tehrani H, Lael-Monfared E, Hosseini Z, Jafari A. The effect of educational intervention on iron and vitamin $D$ consumption based on the theory of planned behaviour in Iranian adolescent girls: a quasi-experimental study. International Journal of Health Promotion and Education. 2019;57(6):316-31. https://doi.org/10.1080/14635240.2019.1632732

24. Ajzen I. The theory of planned behavior. Orgnizational Behaviorand Human Decision Processes, 50, 179-211.1991. https://doi.org/10.1016/0749-5978(91)90020-T

25. Conner M, Armitage CJ. Extending the theory of planned behavior: A review and avenues for further research. Journal of applied social psychology. 1998;28(15):1429-64. https://doi.org/10.1111/j.1559-1816.1998.tb01685.x

26. Cheon J, Lee S, Crooks SM, Song J. An investigation of mobile learning readiness in higher education based on the theory of planned behavior. Computers \& education. 2012;59(3):1054-64. https://doi.org/10.1016/j.compedu.2012.04.015

27. Ammar N, Aly NM, Folayan MO, Khader $\mathrm{Y}$, Virtanen $\mathrm{JI}$, Al-Batayneh OB, et al. Behavior change due to COVID-19 among dental academics-The theory of planned behavior: Stresses, worries, training, and pandemic severity. PloS one. 2020;15(9):e0239961. https://doi.org/10.1371/journal.pone.0239961 PMid:32991611 PMCid:PMC7523990

28. Delshad Noghabi A, Moshki M. The Impact of education on the basis of the theory of planned behavior on the level and method of supervision of their parents on watching television by students. Journal of Health Chimes. 2014;1.

29. peyman $n$, charoghchian khorasani e, moghzi $m$. The Impact of Education on the Basis of the Theory of Planned Behavior on Junk Food Consumption in high school in Chenaran. Razi Journal of Medical Sciences. 2016;23(149):62-72.

30. Vafaeenajar A, Masihabadi M, Moshki M, Ebrahimipour H, Tehrani H, Esmaily H. Determining the theory of planned behavior's predictive power on adolescents' dependence on computer games. Iranian journal of health education and health promotion. 2015;2(4):303-11.

31. Mousavi, K. A Study of Attitudes towards Mobile Phones in Women Living in Tehran, Social Psychological Studies of Women, Vol. 9, No. 3, Winter 2011, pp. 85-110.

32. Sullman $M$, Hill $T$, Stephens $A$. Predicting intentions to text and call while driving using the theory of planned behaviour. Transportation Research Part F: Traffic Psychology and Behaviour. 2018;58:405-13. https://doi.org/10.1016/j.trf.2018.05.002

33. Jiang K, Yang Z, Feng Z, Yu Z, Bao S, Huang Z. Mobile phone use while cycling: a study based on the theory of planned behavior. Transportation research part F: traffic psychology and behaviour. 2019;64:388-400. https://doi.org/10.1016/j.trf.2019.05.020

34. darabi f, yaseri $m$, Kaveh $\mathrm{MH}$, Maheri M. The Effect of Citizenship Education Program Based on Theory of Planned Behavior on High School Female Students in Iran: A Randomized Controlled trial. Iranian Journal of Health Education and Health Promotion. 2018;6(4):429-37. https://doi.org/10.30699/acadpub.ijhehp.6.4.429

35. Hosseini SS, Shamsi M, Khorsandi M, Moradzadeh R. The effect of educational program based on theory of planned behavior on promoting retinopathy preventive behaviors in patients with type 2 diabetes: RCT. BMC Endocrine Disorders. 2021;21(1):17. https://doi.org/10.1186/s12902-021-00680-2 PMid:33446157 PMCid:PMC7809809

36. Shakerinejad G, Baji Z, Tehrani M, Hajinajaf S, Jarvandi F. Effectiveness of an Educational Intervention Based on the Theory of Planned Behavior on the Physical Activities of high school female students. Payesh (Health Monitor). 2017;16(4):511-20.

37. Singh UK, Gautam N, Bhandari TR, Sapkota N. Educational Intervention of Intention Change for Consumption of Junk Food among School Adolescents in Birgunj Metropolitan City, Nepal, Based on Theory of Planned Behaviors. Journal of Nutrition and Metabolism. 2020;2020:7932324. https: / / doi . org / 10.1155 / 2020 / 7932324 PMid:32300487 PMCid:PMC7140134

38. Fakhri A, Morshedi H, Zeidi IM. Effect of an educational 
intervention based on the theory of planned behavior on the use of hearing protection devices. Scientific Journal of Kurdistan University of Medical Sciences. 2017;22(2).

39. Lin L, Lin CC, Chen C, Lin CC, editors. Effects of an education program on intensive care unit nurses' attitudes and behavioral intentions to advocate deceased donor organ donation. Transplantation proceedings; 2014: Elsevier. https://doi.org/10.1016/j.transproceed.2013.12.039 PMid:24815121

40. Hamilton K, van Dongen A, Hagger MS. An extended theory of planned behavior for parent-for-child health behaviors: A meta-analysis. Health Psychology. 2020;39(10):863. https: / / d o i org / 10.1037 / h e a 0000940 PMid:32597678

41. Glanz K, Rimer BK, Viswanath K. Health behavior and health education: theory, research, and practice: John Wiley \& Sons; 2008.

42. Peyman N, Nasehnezhad M. Effect of Education Based on the Theory of Planned Behavior on Fast Food Consumption in High School Girl's Students in Sabzevar City 2014. J Neyshabur Univ Med Sci. 2015;3(3):46-54.

43. Hoseini Soorand A, Miri MR, Sharifzadeh G. Effect of curriculum based on theory of planned behavior, on components of theory in patients with hypertension. Journal of Birjand University of Medical Sciences. 2015;22(3):199-208.

44. Gharaati F, Aghamolaei T, Hassani L, Mohamadi R, Mohsseni S. The effect of educational intervention using mobile phone on self-care behaviors in patients with thalassemia major. Journal of Preventive Medicine. 2016;3(2):63-74 